\title{
PENDATAAN ALUMNI SECARA ONLINE UNTUK MENDAPATKAN DATA TRACER ALUMNI
}

\author{
Primaadi Airlangga ${ }^{1)}$, Mochamad Chumaidi ${ }^{2)}$, Fika Ridaul Maulayya ${ }^{3)}$ \\ ${ }^{10}$ E-mail : unwaha.primaadi@yahoo.com \\ ${ }^{2)}$ E-mail : chumaidi@yahoo.co.id \\ ${ }^{3)}$ E-mail :Fika@yahoo.com
}

\begin{abstract}
Tracer study is a mean to gather information of the alumni on regards to learn about their progress in career, their implementation of skills they learn in their study, and opinion about them from people who work alongside them. The importance of tracer study lies in the processing data from the alumni and producing information that can be used to increase the learning materials, learning methods, motivation of the current students, and quality of service given by the university. Collecting data from graduated University students is not an easy task. The major issue in the data gathering is the distance between the University and the data givers' location because most of them are not grouped in areas near the campus which make them unable to directly submit the questionere to the faculty they studied. Other dificulties faced by the university which conduct tracer study are the alumni's ocupation which prohibit them for going to University, time limit given for the alumni to submit their form, cost used for buying and printing papers, more over the form's layout and content that consist of things that need to be skipped based on options the participant's choice which make it confusing and dificult to gather valid data.

The result of this research is an aplication that can handle the inputs of tracer study by the alumni and produce information about alumni's progress from those inputs, especialy for those who had graduated from their alma mater for more than six months. Several improvement that can be achieved by this application caompared to the previous hand in form method are instant collecting as soon as the user press the submit button, automatic processing which can eliminate submision due date because the user can fill the form any time there is a change in their data, and automatic text and graphical reporting which can be seen anytime with real time update which can be used for producing data for decision making in the university where this application is used.
\end{abstract}

Keyword : angket, alumni, UNWAHA, tracer study, online 


\section{PENDAHUluAN}

Universitas KH.A.Wahab Hasbullah (UNWAHA) sebagai salah satu perguruan tinggi di kabupaten Jombang adalah pilihan terbaik untuk calon mahasiswa baru. UNWAHA adalah universitas yang sangat memperhatikan mutu dan kualitas dengan cara selalu memperhatiakan alumni yang telah terjun didunia Kerja dan masyarakat. Para alumni UNWAHA ketika masih berupa sekolah tinggi masih bisa diawasi dan dibantu oleh sekolah tinggi dalam mengatasi masalah didunia pendidikan dan saat terjun kedalam masyarakat. Dengan berjalannya waktu alumni UNWAHA semakin tahun semakin bertambah seiring dengan usaha dalam peningkatan mutu dan kualitas pendidikan. Banyaknya jumlah alumni memberikan efek semakin sulitnya UNWAHA dalam melakukan pengawasan kepada alumni dan untuk membantu alumni saat berada didunia kerja dan terjun kepada masyarakat.

Pada setahun terakhir setelah perubahan dari sekolah tinggi menjadi sebuah universitas, jumlah alumni UNWAHA menjadi meningkat sangat drastis. Peningkatan alumni melemahkan pemberian bantuan kepada alumni dalam berjuang dalam dunia kerja dan masyarakat. Dengan sulitnya mendapatkan data dari alumni membuat UNWAHA sulit dalam memberikan bantuan kepada alumni, hal ini memberikan motivasi kepada UNWAHA untuk membangun sebuah system baru melalui tracer.unwaha.ac.id guna melacak bagaimana keadaan dan kualitas alumni setelah menyelesaikan meja perkuliahan.

Penggunaan formulir angket pada tahun-tahun sebelumnya memberikan pengalaman bagi universitas karena saat pemberian formulir sering terjadi kerusakan formulir dikarenakan kesalahan pengisian dan rawan kesalahan dalam pemahaman tentang memahami instruksi.

Pemberian angket kepada alumni harus dilakukan secara terus menerus guna meningkatkan kualitas dan mutu universitas dengan begitu penghitungan, pengkategorian, dan penyajian data yang harus dilakukan terus menerus. Dengan adanya tracer.unwaha.ac.id diharapkan dapat dengan mudah melakukan penghitungan, pengkategorian, dan penyajian data tanpa ada kesalahan karena telah menjadi sebuah system sehingga bisa lebih mudah mengetahui bagaimana kualitas alumni UNWAHA sehingga UNWAHA tetap bisa meningkatkan kualitas dan mutu pendidikan dengan menggunakan system ini.

\section{RUMUSAN MASALAH}

Berdasarkan uraian yang tercantum pada pendahuluan maka masalah yang dihadapi saat ini adalah:

1. Sulitnya mendapatkan data dari alumni UNWAHA.

2. Lembar formulir yang rawan kesalahan dikarenakan banyaknya isian dan sedikitnya instruksi.

3. Penghitungan, pengkategorian, dan penyajian data yang harus dilakukan terus menerus secara manual setiap kali ada data baru yang masuk untuk mendapatkan informasi mengenai tracer study alumninya.

\section{BATASAN MASALAH}

Penelitian ini memiliki batasan sebagai berikut:

1. Hanya menggunakan media web untuk pengaksesannya.

2. Hanya diterapkan di Program Studi Sistem Informasi dan Teknik Informatika UNWAHA Jombang sebagai studi kasusnya.

\section{LANDASAN TEORI}

a. CSS

CSS adalah bahasa yang digunakan untuk mengatur tampilan tiap-tiap tag html agar dapat menghasilkan tampilan dari tag html yang nyaman untuk dipandang. 
Dengan pengaturan tampilan tag dengan menggunakan css, bisa membantu pemirsa atau pengunjung web tertarik pada web sehingga secara tak langsung membantu menaikkan rating kunjungan. Pengunjung yang telah tertarik dapat mempermudah web site untuk berinteraksi dengan pengunjung sehingga website bisa melakukan manfaat sesuai dengan tujuan pembuatan website.

\section{b. Java Script}

Java script adalah kode yang dijalankan oleh browser untuk mengubah tampilan sebuah web yang mana kode tersebut dijalankan pada masing-masing perangkat yang mengakses situs tersebut. Javascript berguna karena lebih ringan daripada PHP dikarenakan pengeksekusian kodenya dilakukan di komputer pengguna dan bisa merubah tampilan tanpa harus berpindah halaman.

Fungsi utama java script dalam applikasi ini adalah akan digunakan bersamaan dengan CSS untuk menyembunyikan isian yang hanya bisa diakses ketika user memilih pilihan tertentu dari formulir yang disediakan. Pentingnya penyembunyian isian formulir adalah agar pengisi tidak perlu mengisi isian yang tidak perlu sehingga mengurangi kesalahan dan waktu pengerjaan.

\section{c. MySQL}

MySQL adalah salah satu Data Base Management Sistem(DBMS) gratis yang memiliki kemampuan sangat bagus dan dapat mencukupi kebutuhan akan menejemen database dalam pengembangan perangkat lunak. mysql sebagai DBMS opensource memberikan berbagai kemudahan kepada pengguna senhingga pengguna tidak perlu khawatir akan lisensi dan kebutuhan sumberinformasi tentang mysql karena ada banyak bantuan sumberdaya untuk DBMS mysql.

Penggunaan mysql sebagai DBMS dalam pengembangan perangkat lunak sangat bagus karena mysql memiliki kelebihan antara lain ringan, memiliki kecepatan akses tinggi, portabel, mudah untuk mendapat bantuan informasi.

\section{d. PHP}

PHP kepanjangan dari Personal Home Page, merupakan bahasa pemrogaman web yang disisipkan kedalam HTML yang dijalankan pada komputer server. PHP memberikan banyak kemudahan bagi para pengembang web dikarenakan banyak sumber informasi yang disediakan melalui internet dan telah mendukung bentuk pemrogaman berorientasi objek. PHP juga telah didukung oleh banyak web server seperti apache, IIS, Lighttpd hingga Xitami dengan kemudahan dalam melakukan konfigurasi dan php juga dapat dijalankan di berbagai OS karena merupakan bahasa pemrogaman yang open source. Dengan kemudahan-kemudahan yang diberikan oleh php menjadikan bahasa pemrogaman ini menjadi pilihan terbaik untuk membangun suatu web.

\section{e. Tracer Study}

Tracer Study adalah kegiatan sebuah lembaga pendidikan tinggi untuk mengetahui daya serap lulusan dalam dunia kerja. Tracer study ini adalah salah satu tujuan diciptaannya appliasi ini.

Beberapa hal yang diharapkan untuk didapat dari angket ini adalah lama tunggu lulusan UNWAHA untuk diterima sebagai karyawan atau menciptakan lapangan kerja sendiri, mengetahui pengguna-pengguna lulusan yang nantinya dapat dijadikan target lulusanlulusan berikutnya dari lembaga Perguruan Tinggi, kisaran gaji yang didapat dari lulusan prodi-prodi di UNWAHA, serta umpan balik pengguna lulusan terhadap kinerja, moral dan kemampuan lainnya dari alumni UNWAHA. 


\section{IMPLEMENTASI}

Daftar Tabel

Tabel 4.1 Angket Form 1 dan Umpan Balik

\begin{tabular}{|c|c|c|c|}
\hline Nama Field & Type Data & Size & Keterangan \\
\hline $\mathrm{Nim}$ & Varchar & 20 & NIM Mahasasiswa \\
\hline Nama & Varchar & 225 & Nama Mahasiswa \\
\hline Tlulus & Varchar & 20 & Tahun lulus \\
\hline Trumah & Varchar & 20 & Telp Rumah \\
\hline Thp & Varchar & 20 & Telp Hp \\
\hline Email & Varchar & 100 & Email \\
\hline Kontak & Varchar & 255 & Kontak lainnya \\
\hline Kerja & Tinyint & 1 & Status Kerja \\
\hline Alasan & Varchar & 225 & Alasan Kerja \\
\hline Alamat & Varchar & 255 & Alamat Rumah \\
\hline Telephone & Varchar & 20 & Telephone \\
\hline Prodi & Tinyint & 1 & Prodi \\
\hline Kesulitan_pertama & Varchar & 225 & Kesulitan \\
\hline Kemampuan_keahlian & Varchar & 100 & Kemampuan Keahlian \\
\hline $\begin{array}{l}\text { Kemampuan_kerjasa } \\
\text { ma }\end{array}$ & Varchar & 100 & $\begin{array}{l}\text { Kemampuan Kerja } \\
\text { sama }\end{array}$ \\
\hline $\begin{array}{l}\text { Kemampuan_komunik } \\
\text { asi }\end{array}$ & Varchar & 100 & $\begin{array}{l}\text { Kemampuan } \\
\text { Komunikasi }\end{array}$ \\
\hline Kemampuan_moral & Varchar & 100 & Kemampuan Moral \\
\hline Kemampuan_bing & Varchar & 100 & $\begin{array}{l}\text { Kemampuan Bahasa } \\
\text { Inggris }\end{array}$ \\
\hline Pengembangan_diri & Varchar & 100 & Pengembangan Diri \\
\hline Kurikulum & Varchar & 100 & Kurikulum \\
\hline Saran & Text & - & Saran \\
\hline
\end{tabular}

Tabel 4.2 Angket 2A

\begin{tabular}{|l|l|l|l|}
\hline \multicolumn{1}{|c|}{ Nama Field } & \multicolumn{1}{c|}{ Type Data } & \multicolumn{1}{c|}{ Size } & \multicolumn{1}{c|}{ Keterangan } \\
\hline Menunggu_kerja & Varchar & 100 & Lama Menunggu Kerja \\
\hline Nama_perusahaan & Varchar & 100 & Nama Perusahaan \\
\hline Bentuk_perusahaan & Varchar & 100 & Bentuk perusahaan \\
\hline Bidang_pekerjaan_ti & Varchar & 100 & Bidang Pekerjaan TI \\
\hline Bidang_pekerjaannon_ti & Varchar & 100 & Bidang Pekerjaan Non TI \\
\hline Jabatan_pertama & Varchar & 100 & Jabatan Saat Pertama Kerja \\
\hline Income_pertama & Varchar & 100 & Perkiraan Income Pertama \\
\hline Perusahaan_tetap & Varchar & 100 & Perusahaan Pertama \\
\hline Jabatan_saat_ini & Varchar & 100 & Jabatan Saat ini \\
\hline Perkiraan_income & Varchar & 100 & Perkiraan Income / Pendapatan \\
\hline
\end{tabular}




\begin{tabular}{|l|l|l|l|}
\hline Pindah_kerja & Varchar & 100 & Saat ini Pindah Kerja Berapa Kali \\
\hline Perushaan_Sekarang & Vrachar & 100 & Nama Perusahaan Sekarang \\
\hline Jabatan_perusahaan_sekarang & Varchar & 100 & Jabatan di Perusahaan Sekarang \\
\hline Bentuk_perusahaan_Sekarang & Varchar & 100 & Bentuk Perusahaan Sekarang \\
\hline Bidang_pekerjaan_ti_sekarang & Varchar & 100 & Bidang Pekerjaan TI Sekarang \\
\hline $\begin{array}{l}\text { Bidang_pekerjaan_nonti_sekar } \\
\text { ang }\end{array}$ & Varchar & 100 & Bidang Pekerjaan Non TI Sekarang \\
\hline
\end{tabular}

Tabel 4.3 Angket 2B

\begin{tabular}{|l|l|l|l|}
\hline \multicolumn{1}{|c|}{ Nama Field } & \multicolumn{1}{c|}{ Type Data } & \multicolumn{1}{c|}{ Size } & \multicolumn{1}{c|}{ Keterangan } \\
\hline Jenis_perusahaan & Varchar & 100 & Jenis Peusahaan Saudara \\
\hline Bidang_usaha & Varchar & 100 & Bidang Usaha Saudara \\
\hline Waktu_mendirikan & Varchar & 100 & Waktu Mendirikan Usaha \\
\hline Jumlah_karyawan & Varchar & 100 & Jumlah karyawan \\
\hline Karyawan_sarjana & Varchar & 100 & Jumlah karyawan sarjana \\
\hline Karyawan_diploma & Varchar & 100 & Jumlah karyawan diploma \\
\hline Karyawan_smu & Varchar & 100 & Jumlah karyawan SMU/SMK \\
\hline Aset_perusahaan & Varchar & 100 & Jumlah Aset Perusahaan \\
\hline
\end{tabular}
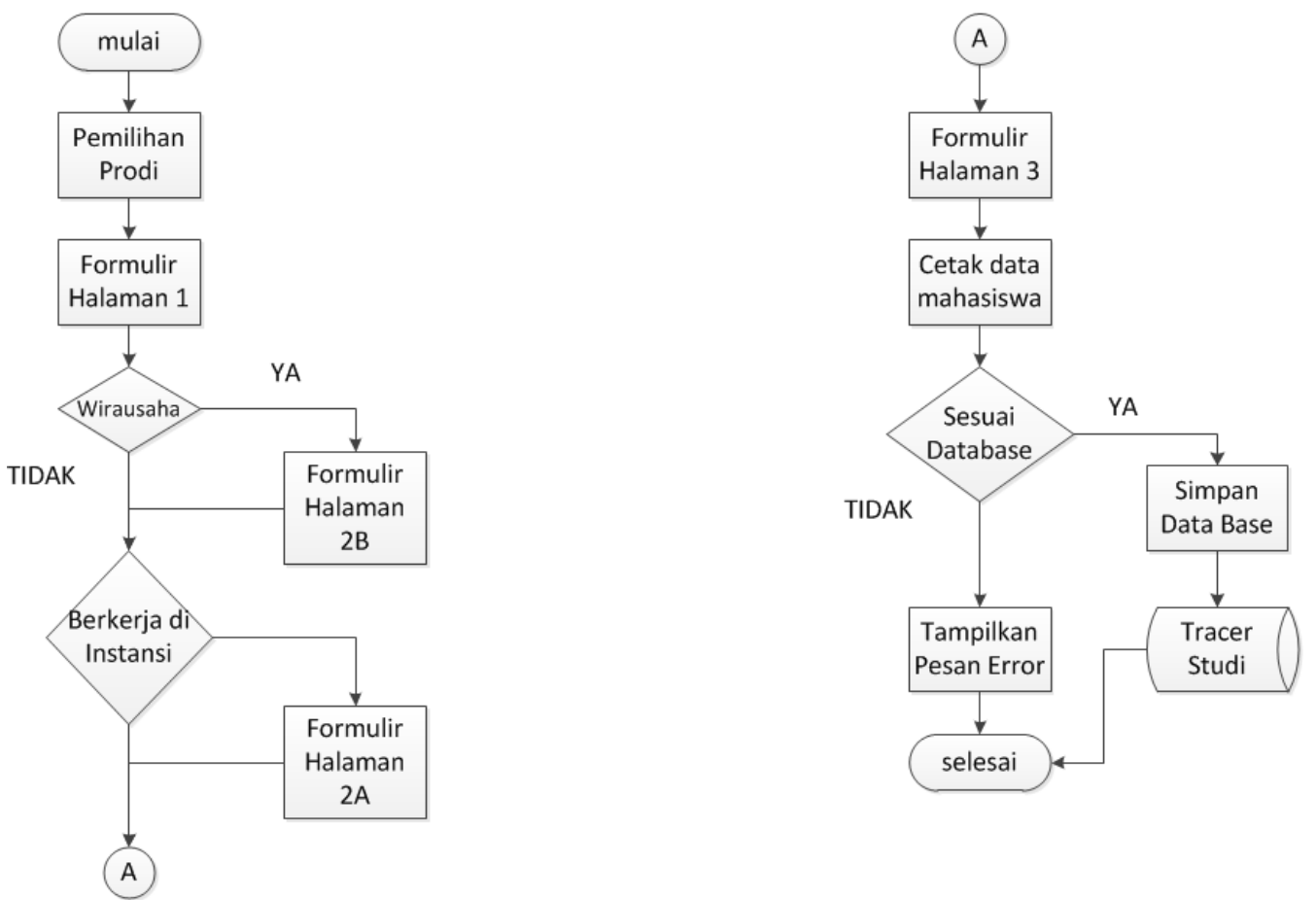

Gambar 4.1 Diagram Pengisian Tracer Study 


\section{Halaman Depan}

1. Home

Berikut adalah tampilan yang akan dilihat oleh pengguna ketika menggunakan sistem:

Pada halaman depan, saat pertama kali mengunjungi situs, pengunjung diarahkan pada halaman home. Pengunjung dapat memilih fakultas dan prodi almamater mereka untuk mengisi Tracer Study pada prodi tersebut.

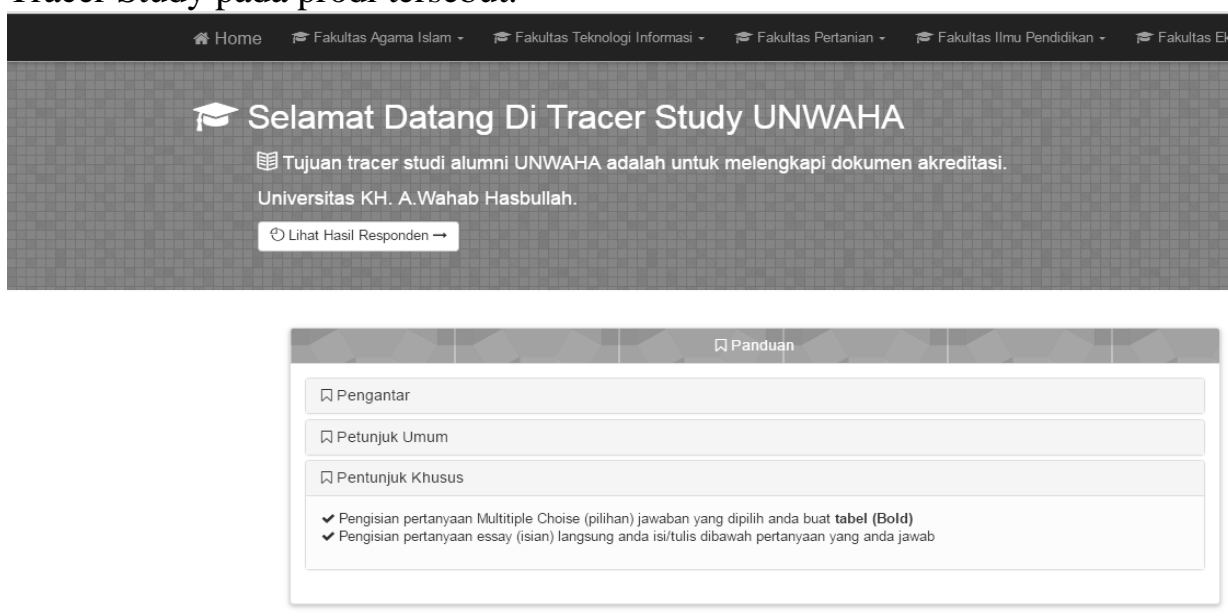

Gambar 4.2 Home

\section{Form Angket}

Form isian angket yang akan diisi oleh alumni terbagi menjadi 3 halaman yang dinamis. Halaman pertama berisikan tentang data diri dan status pekerjaan. Berdasarkan status pekerjaan pengguna akan diarahkan kehalaman 2A, 2B, atau langsung pada halaman umpan balik (seperti tertera pada gambar 4.1: Diagram Pengisian tracer Study ).

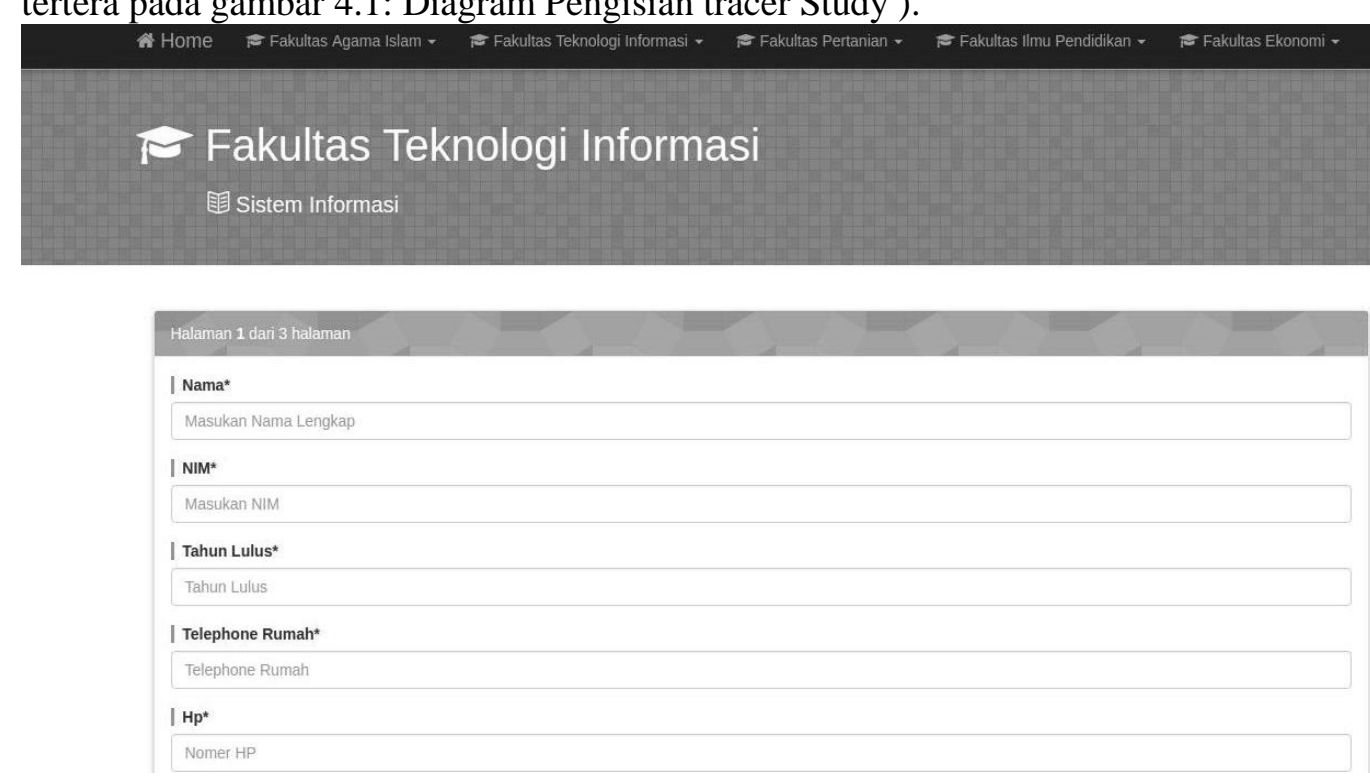

Gambar 4.3 Form Angket

\section{Halaman Hasil Responden}

Pengguna informasi Tracer Study keseluruhan dari sebuah Program Studi dengan cara memilih data prodi yang ingin dilihat. 


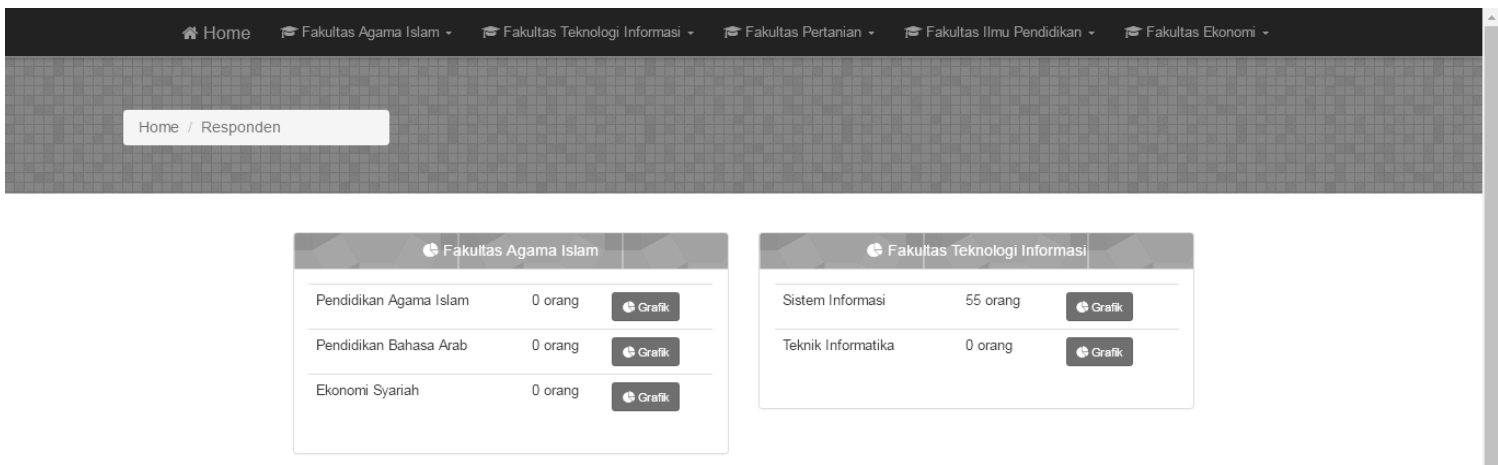

Gambar 4.4 Hasil Responden

3. Diagram Responden

Hasil perhitungan angket akan langsung dimunculkan pada halaman ini berupa diagram. Angka-angka detail mengenai diagram dapat diakses dengan menekan tombol detail data dibawah diagram.

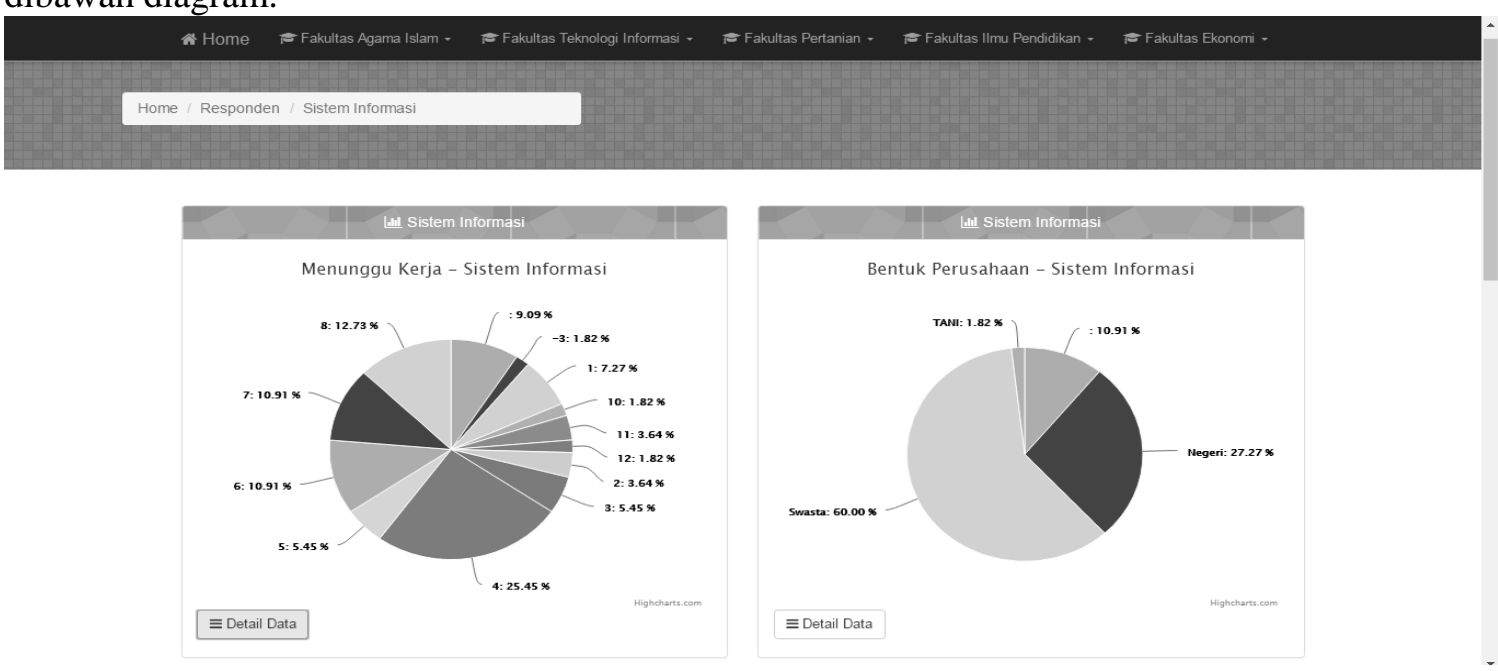

Gambar 4.5 Diagram Responden

\section{Halaman Belakang}

1. Halaman Login

Admin melakukan login untuk melakukan konfigurasi.

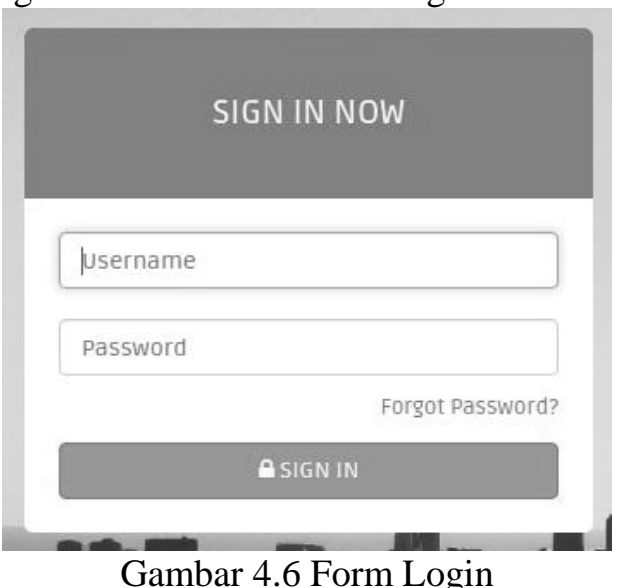


2. Halaman Admin

Halaman Admin untuk melakukan konfigurasi tracer.
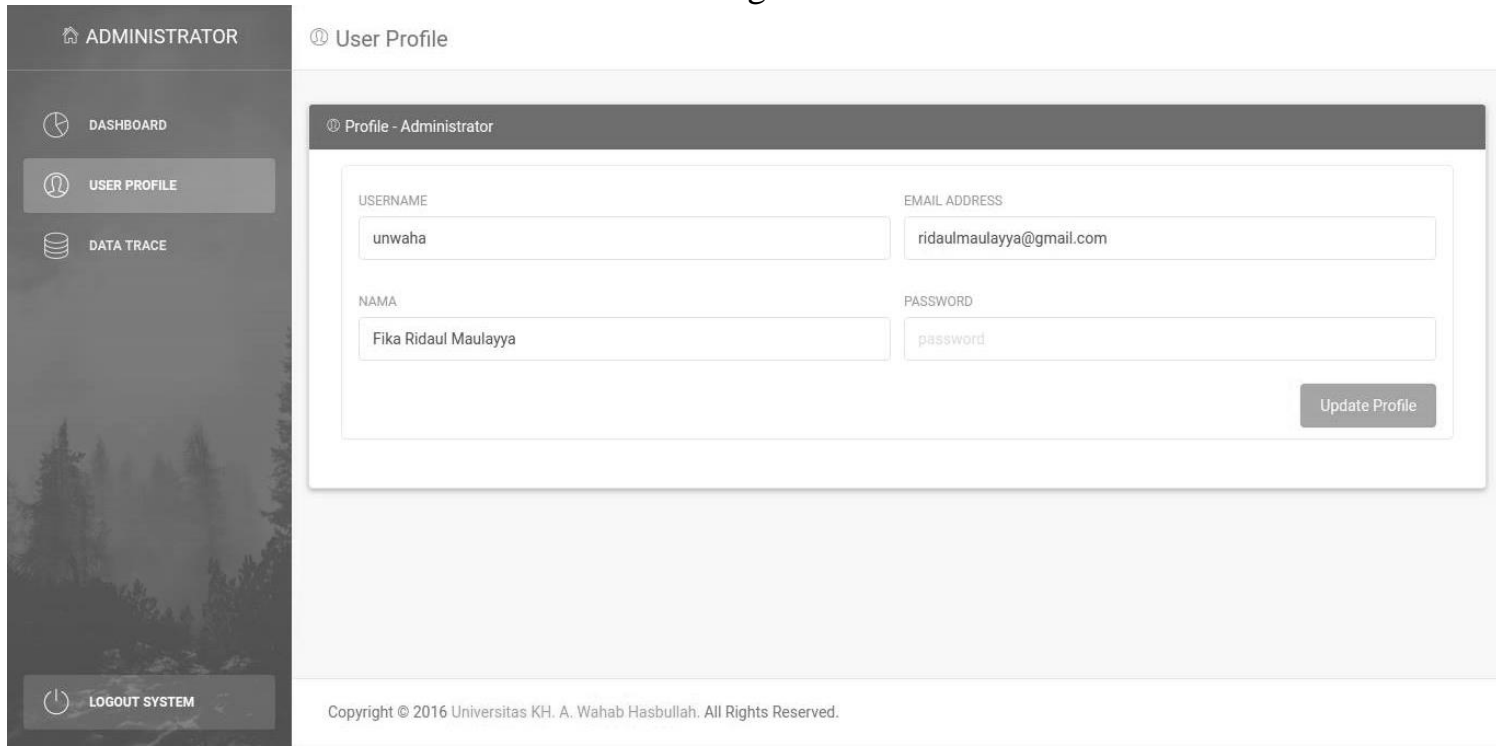

Gambar 4.7 Halaman Admin

\section{Halaman Data Tracer}

Halaman Data Trace berisi data alumni atau angket alumni dan sebagai laporan dapat dicetak atau menjadi file PDF.

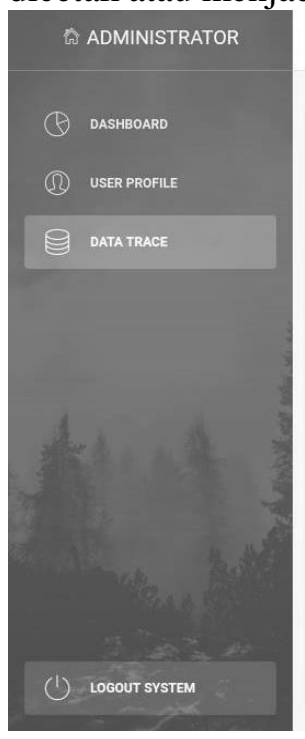

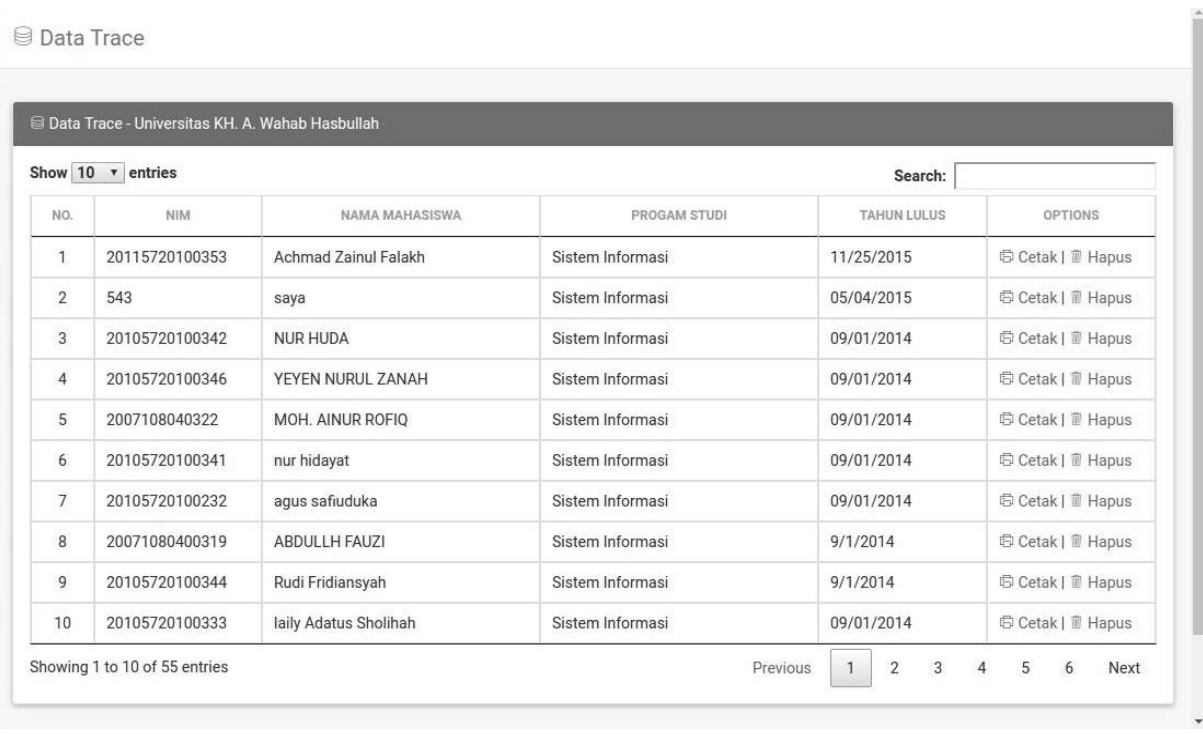

Gambar 4.8 Halaman Data Tracer

\section{PENUTUP}

\section{Kesimpulan}

Setelah menerapkan applikasi hasil dari penelitian ini dapat disimpulkan:

1. Dengan bantuan media sosial dan pemberitahuan secara langsung para alumni dapat langsung mengisi data mereka tanpa harus datang ke kampus UNWAHA. 
2. Tidak ada kesulitan berarti pada saat pengisian data. Adapun kesulitan yang dihadapi terletak pada infomasi nomor telepon mahasiswa yang sudah tidak aktif lagi dan harus mencari melalui orang-orang dekat alumni.

3. Informasi yang diberikan oleh aplikasi ini cukup mudah dipahami dan berguna untuk menentukan mata kuliah dalam rapat perbaikan kurikulum.

\section{Saran}

Beberapa hal yang perlu dipertimbangkan bagi pengguna applikasi ini dan juga untuk pengembangan applikasi ini kedepan:

1. Diharapkan bentuk dan pertanyaan dalam formulir terus disesuaikan dengan perkembangan kebutuhan agar informsi yang dihasilkan aplikasi ini tetap berguna, dan perlu disesuaikan dengan teknologi yang ada untuk memudahkan pengguna dalam memasukkan data.

2. Perlu dilakukan penyimpanan data cadangan sebagai mitigasi terhadap gangguan dari dalam maupun luar sistem.

3. Harap pemuatan data dilakukan dengan sungguh-sungguh dan berdasarkan fakta agar keputusan yang diambil dapat membantu berkembangnya lembaga pendidikan.

\section{DAFTAR PUSTAKA}

Alatas, H. 2015. Proyek membangun responsive web design dengan bootstrap 3 \& 4. Jakarta:

Lokomedia.

Prasetio, A. 2012. Buku Pintar Pemrograman Web. Jakarta: MediaKita.

Utomo, M,S. 2012. Implementasi PHP sebagai Penghasil Konten Otomatis pada Halaman

Situs. Semarang: UNIVERSITAS STIKUBANK, Dinamik - Jurnal Teknologi Informasi.

Naista, D. 2016. Bikin Framework PHP Sendiri dengan Teknik OOP dan MVC. Jakarta:

Lokomedia 